\title{
Mathematics achievement and Disciplinary Alternative Education Program placement of grades 3 through 8 students with disabilities: A Texas statewide, multiyear examination
}

\author{
Jamie Heintz Benson $^{1} \quad$ John R. Slate ${ }^{1^{*}} \quad$ George W. Moore $^{1} \quad$ Cynthia Martinez-Garcia $^{1}$ \\ Frederick C. Lunenburg ${ }^{1}$
}

\begin{abstract}
In this investigation, the mathematics performance of Grades 3 through 8 students who were enrolled in special education and who were assigned to a Discipline Alternate Education Program placement was addressed. Four years of Texas statewide data were analyzed by the number of days (i.e., 1-30 days, 31-60 days, and more than 60 days) students in special education received this discipline consequence. Across all four school years and for all six grade levels, mathematics performance decreased as students spent more days in this discipline consequence. Implications of these findings are discussed, along with recommendations for future research.
\end{abstract}

Keywords: special education, Discipline Alternative Education Program placement, mathematics achievement, grade 3, 4, 5, 6, 7 and 8, school years 2012-2013, 2013-2014, 2014-2015 and 2015-2016

\section{Introduction}

Students with disabilities were more than twice as likely to receive an out-of-school suspension than were their counterparts who did not have a disability (National Council on Disability, 2015). For instance, in the 20112012 school year, students who were enrolled in special education represented a quarter of school-related arrests. Moreover, only $61 \%$ of students in special education graduated high school, a much lower rate than the $80 \%$ graduation rate of their peers without a disability. As exclusionary discipline assignments increased, graduation rates decreased. The National Council on Disability in 2015 reported that in the 2009-2010 school year, $13 \%$ of students who were enrolled in special education in the United States were assigned an out-of-school suspension, almost double the percentage of students who were not enrolled in special education and who were assigned an out-of-school suspension ${ }^{[1]}$.

\footnotetext{
Received: Nov. 20, 2019; Accepted: Dec. 23, 2019; Published: Dec. 26, 2019 Correspondence to: John R. Slate, Sam Houston State University, United States; Email: profslate@aol.com

${ }^{1}$ Sam Houston State University, United States.

Citation: Benson JH, Slate JR, Moore JW, et al. Mathematics achievement and Disciplinary Alternative Education Program placement of grades 3 through 8 students with disabilities: A Texas statewide, multiyear examination. Adv Educ Res Eval, 2019, 1(1): $12-23$.

Copyright: $\odot 2019$ John R. Slate, et al. This is an open access article distributed under the terms of the Creative Commons Attribution License, which permits unrestricted use, credited.
}

Federal legislation was established to protect students enrolled in special education from lengthy exclusionary discipline assignments. The Individuals with Disabilities Education Act was reauthorized in 1997 providing school districts with the ability to exclude students with disabilities from the classroom as a discipline consequence for up to 10 days without requiring a meeting to review and possibly revise the student's individual education plan ${ }^{[2]}$. According to the National Council on Disability in $2015^{[1]}$, included in the Individuals with Disabilities Education Act ${ }^{[2]}$ is the statement that school districts should "provide an education that is specially designed to meet a student's unique needs supported by services that will permit him or her to benefit instruction". The National Council on Disability in 2015 argued allowing students to be excluded from the regular classroom setting for up to 10 days is a failure to provide students with a free and appropriate public education $^{[1]}$. During the reauthorization of the Individuals with Disabilities Education Act in $1997^{[2]}$, Senator Edward Kennedy stated, "Discipline should never be used as an excuse to exclude or segregate students with disabilities because of failure to design behavioral management plans, or the failure to provide support services and staff training" (National Council on Disability, 2015, p. 18). Following the reauthorization of the Individuals with Disabilities Education Act, students enrolled in special education continued to receive exclusionary dis- 
cipline assignments ${ }^{[2]}$.

The Individuals with Disabilities Education Act was established to ensure students with disabilities receive the same educational opportunities as their non-disabled peers. This federal legislation was implemented to ensure students enrolled in special education have opportunities within the classroom along-side their non-disabled peers. Exclusion from the classroom due to discipline assignments would make it difficult for students enrolled in special education to perform academically (Individuals with Disabilities Education Act, 2004) ${ }^{[2]}$.

In a recent analysis of the relationship of discipline consequence assignment and academic achievement for students in special education, Benson and Slate ${ }^{[3]}$ examined data on Grade 9 White, Black, and Hispanic students with a Learning Disability in the 2008-2009 school year. In their investigation, Benson and Slate ${ }^{[3]}$ analyzed the mathematics test scores for these three groups of Grade 9 students with a Learning Disability based on whether or not they had been assigned to an in-school suspension or to an out-of-school suspension. White, Black, and Hispanic students with a Learning Disability who were assigned to an in-school suspension had statistically significantly lower mathematics test scores than their counterparts with a Learning Disability who were not assigned to an in-school suspension. In particular, White students who were assigned to an in-school suspension had an average mathematics score that was 77 points lower than White students who were not assigned to an in-school suspension. Hispanic students who were assigned to an in-school suspension had an average mathematics score that was 49 points lower than Hispanic students who were not assigned to an in-school suspension. Black students who were assigned in-school suspension had an average mathematics score almost 36 points lower than their counterparts who were assigned in-school suspension.

When examining the effects of out-of-school suspension, Benson and Slate ${ }^{[3]}$ established that White, Black, and Hispanic students who had a Learning Disability and who were assigned to an out-of-school suspension had statistically significantly lower average mathematics test scores than White, Black, and Hispanic students who had a Learning Disability and who were not assigned to an out-of-school suspension. Specifically, White students who had a Learning Disability and who were assigned to an out-of-school suspension had an average mathematics score that was 107 points lower than White students with a Learning Disability who were not assigned to an out-of-school suspension. Hispanic students who had a Learning Disability and who were assigned to an out-ofschool suspension had an average mathematics score that was almost 88 points lower than Hispanic students with a Learning Disability who were not assigned to an out-ofschool suspension. Finally, Black students with a Learning Disability who were assigned to an out-of-school suspension had an average mathematics score that was 81 points lower than Black students with a Learning Disability who were not assigned to an out-of-school suspension. As such, Benson and Slate ${ }^{[3]}$ determined that the mathematics achievement of Grade 9 students with a Learning Disability was influenced by the receipt of in-school suspension and by the receipt of out-of-school suspension.

In a similar study, Allman and Slate ${ }^{[4]}$ investigated the relationship of exclusionary discipline assignments on the mathematics achievement of Grade 9 students with disabilities. The discipline consequences they focused on were in-school suspension, out-of-school suspension, and Disciplinary Alternative Education Program placement. Allman and Slate ${ }^{[4]}$ analyzed the effect of each disciplinary consequence separately on student mathematics achievement. Students with disabilities who received an in-school suspension had an average mathematics score that was almost 60 points lower than their counterparts who were not assigned to an in-school suspension. Students with disabilities who were assigned to an out-of-school suspension had an average mathematics score that was almost 100 points lower than their counterparts with disabilities who were not assigned to an out-of-school suspension. Finally, students with disabilities who were assigned to a Disciplinary Alternative Education Program placement had an average mathematics score that was almost 118 points lower than their counterparts with disabilities who were not assigned to a Disciplinary Alternative Education Program placement. As such, clear evidence was present that students with a disability and who were assigned to an in-school suspension, to an out-of-school suspension, or to a Disciplinary Alternative Education Program placement had statistically significantly lower mathematics performance than their counterparts with a disability who was not assigned any of these three discipline consequences.

In a follow up study, Allman and Slate ${ }^{[5]}$ investigated the relationship of three discipline consequences (i.e., inschool suspension, out-of-school suspension, and Disciplinary Alternative Education Program placement) with the mathematics achievement of Texas Grade 9 students who qualified as having a Learning Disability, Emotional Disorder, or Other Health Impairment. When examining the effect of exclusionary discipline assignments on students enrolled in special education as a function of disability type, Allman and Slate ${ }^{[5]}$ established that all three groups of students with a disability had statistically sig- 
nificantly lower mathematics test performance than their peers with disabilities who were not assigned to any of these discipline consequences.

In regard to the influence of exclusionary discipline assignments on mathematics achievement, students who had a Learning Disability and who were assigned to an in-school suspension had an average mathematics score that was 59 points lower than their counterparts with a Learning Disability and who were not assigned to an in-school suspension. Students who were Emotionally Disturbed and who were assigned to an in-school suspension had an average mathematics score that was 52 points lower than their counterparts who were Emotionally Disturbed and who were not assigned to an in-school suspension. Students who were Other Health Impaired and who were assigned to an in-school suspension had an average mathematics score that was 62 points lower than their counterparts with an Other Health Impairment who were not assigned to an in-school suspension.

Concerning out-of-school suspension and mathematics achievement, students who had a Learning Disability and who were assigned to an out-of-school suspension had an average mathematics score that was almost 98 points lower than their counterparts with a Learning Disability who were not assigned to an out-of-school suspension. Students who were Emotionally Disturbed and who were assigned to an out-of-school suspension had an average mathematics score that was almost 105 points lower than their counterparts who were Emotionally Disturbed and who were not assigned out-of-school suspension. Students who were Other Health Impaired and were assigned to an out-of-school suspension had an average mathematics score that was almost 100 points lower than their counterparts who were Other Health Impaired and who were not assigned to an out-of-school suspension.

In regard to Disciplinary Alternative Education Program placement and mathematics achievement, students who were Learning Disabled and were assigned to an out-of-school suspension had an average mathematics score that was almost 117 points lower than their counterparts with a Learning Disability and who were not assigned to a Disciplinary Alternative Education Program placement. Students who were Emotionally Disturbed and who were assigned to a Disciplinary Alternative Education Program placement had an average mathematics score that was 103 points lower than their counterparts who were Emotionally Disturbed and who were not assigned to a Disciplinary Alternative Education Program placement. Students who were Other Health Impaired and were assigned to a Disciplinary Alternative Education Program placement had an average mathemat- ics score that was 132 points lower than their counterparts who were Other Health Impaired and who were not assigned to a Disciplinary Alternative Education Program placement. In their statewide analysis, Allman and Slate ${ }^{[5]}$ established that exclusionary discipline assignments were clearly related to the mathematics achievement of students with disabilities.

\subsection{Statement of the problem}

Students who are enrolled in special education are less likely to acquire academic and functional skills at the same rate as their peers who are not enrolled in special education. Students who were enrolled in special education are more likely to receive exclusionary discipline assignments than their peers without disabilities ${ }^{[6,7]}$. Exclusion from the classroom will only decrease their exposure to typically developing peers and make academic tasks even more difficult. Allman and Slate ${ }^{[4]}$ provided evidence that exclusionary discipline assignments are clearly related to the mathematics achievement of students enrolled in special education. In a follow up study, Allman and Slate ${ }^{[5]}$ established that Grade 9 students who had a Learning Disability, Emotional Disturbance, or Other Heath Impairment had statistically significantly lower mathematics test scores when they were assigned to an exclusionary discipline consequence than their counterparts who were not assigned to an exclusionary discipline consequence. Given the recent changes in the Texas state-mandated assessments, current information is needed to determine the effect of exclusionary discipline assignments on the mathematics achievement of students enrolled in special education. Such information would be useful to determine the extent to which progress has been made in using alternatives to exclusionary discipline and decreasing the effect of exclusionary discipline assignments on the mathematics achievement of students enrolled in special education.

Student mathematics performance in this article was defined as their mathematics test scores on the current Texas state-mandated assessment. The Texas Education Agency ${ }^{[8]}$ (2017b) defined The State of Texas Assessment of Academic Readiness (STAAR) as a state readiness program implemented by the Texas Education Agency in the 2011-2012 school year. This assessment was designed to measure the extent to which students have learned and are able to apply knowledge and skills defined by the Texas Essential Knowledge and Skills. For this investigation, the level of academic performance is categorized by three levels that describe student performance. On the STAAR exam, the level of Level I Unsatisfactory Academic Performance is assigned to stu- 
dents who are inadequately prepared and who are unlikely to succeed in the next grade level. Level II Satisfactory Academic Performance refers to the label given to students who are prepared for the next grade level. Level II: Phase-In Satisfactory Performance refers to the label given to students who are prepared for the next grade level, by Phase-In standards. The Phase-In Standard is 1.0 standard deviations below the Level II Recommended Performance standard reported to be established in the 2021-2022 school year (Texas Education Agency, 2015) ${ }^{[9]}$. The label of Level III Advanced Academic Performance is given to students who are wellprepared for the next grade level and who have a high likelihood of success with little intervention (Texas Education Agency, 2016a) ${ }^{[10]}$.

\subsection{Purpose of the study}

The purpose of this study was to determine the performance of students in special education who received between 1 to 30 days in a Disciplinary Alternative Education Program placement on their STAAR Mathematics Level I: Unsatisfactory, STAAR Mathematics Level II: Satisfactory, STAAR Mathematics Level II: PhaseIn Satisfactory, and STAAR Mathematics Level III: Advanced performance. A second purpose of this study was to ascertain the performance of students in special education who received between 11 and 60 days in a Disciplinary Alternative Education Program placement on their STAAR Mathematics Level I: Unsatisfactory, STAAR Mathematics Level II: Satisfactory, STAAR Mathematics Level II: Phase-In Satisfactory, and STAAR Mathematics Level III: Advanced performance. The final purpose of this study was to determine the performance of students in special education who received more than days in a Disciplinary Alternative Education Program placement on their STAAR Mathematics Level I: Unsatisfactory, STAAR Mathematics Level II: Satisfactory, STAAR Mathematics Level II: PhaseIn Satisfactory, and STAAR Mathematics Level III: Advanced standards. The mathematics achievement of students enrolled in special education was analyzed separately for Grades 3 through 8. The influence of exclusionary discipline assignments on the mathematics achievement of students with disabilities was also analyzed separately for the 2005-2006 through 2015-2016 school years.

\subsection{Significance of the study}

Research providing current information concerning the relationship of exclusionary discipline practices on the mathematics achievement of students enrolled in spe- cial education is sparse. Very few empirical research investigations are in the extant literature in which the relationship of exclusionary discipline assignments with the mathematics achievement of students in special education has been addressed. Current evidence on the exclusionary discipline assignments of students enrolled in special education and influence on the mathematics achievement is needed, particularly for the State of Texas. Exclusionary discipline assignments and how the effect of these assignments varies when considering the duration of exclusionary assignment was investigated. The effect of exclusionary discipline assignments on mathematics achievement over time was examined. Trends concerning discipline assignments and mathematics achievement for the 2012-2013 through the 2015-2016 school years were investigated.

\subsection{Research questions}

The following research questions were addressed in this study: (a) What is the percentage of students in special education who had STAAR Mathematics Level I: Unsatisfactory Standard performance and received between 1 to 30 days in a Disciplinary Alternative Education Program placement?; (b) What is the percentage of students in special education who had STAAR Mathematics Level I: Unsatisfactory Standard performance and received between 31 to 60 days in a Disciplinary Alternative Education Program placement?; (c) What is the percentage of students in special education who had STAAR Mathematics Level I: Unsatisfactory Standard performance and received more than 60 days in a Disciplinary Alternative Education Program placement?; (d) What is the percentage of students in special education who had STAAR Mathematics Level II: Satisfactory Standard performance and received between 1 to 30 days in a Disciplinary Alternative Education Program placement?; (e) What is the percentage of students in special education who had STAAR Mathematics Level II: Satisfactory Standard performance and received between 31 to 60 days in a Disciplinary Alternative Education Program placement?; (f) What is the percentage of students in special education who had STAAR Mathematics Level II: Satisfactory Standard performance and received more than 60 days in a Disciplinary Alternative Education Program placement?; (g) What is the percentage of students in special education who had STAAR Mathematics Level II: Phase-In Satisfactory Standard performance and received between 1 to 30 days in a Disciplinary Alternative Education Program placement?; (h) What is the percentage of students in special education who had STAAR Mathematics Level II: Phase-In Sat- 
isfactory Standard performance and received between 31 to 60 days in a Disciplinary Alternative Education Program placement?; and (i) What is the percentage of students in special education who had STAAR Mathematics Level II: Phase-In Satisfactory Standard performance and received more than 60 days in a Disciplinary Alternative Education Program placement?; (j) What is the percentage of students in special education who had STAAR Mathematics Level III: Advanced Standard performance and received between 1 to 30 days in a Disciplinary Alternative Education Program placement?; (k) What is the percentage of students in special education who had STAAR Mathematics Level III: Advanced Standard performance and received between 31 to 60 days in a Disciplinary Alternative Education Program placement?; and (l) What is the percentage of students in special education who had STAAR Mathematics Level III: Advanced Standard performance and received more than 60 days in a Disciplinary Alternative Education Program placement? These research questions were repeated for students in Grades 3, 4, 5, 6, 7, and 8. These research questions were also repeated for the 2012-2013 through 2015-2016 school years.

\section{Method}

\subsection{Research design}

In this investigation, a descriptive approach (Creswell, 2009) was used to answer the previously discussed research questions ${ }^{[11]}$. In that approach, the relationship of Disciplinary Alternative Education Program placement on the mathematics achievement of students enrolled in special education during the 2012-2013 through 20152016 school years was calculated. When using a descriptive approach, large amounts of data can be analyzed. The outcomes of these analyses are descriptive information in which the available data are summarized.

Limitations are clearly present in a descriptive research design (Creswell, 2009) ${ }^{[11]}$. The data that were analyzed in this article can only be described and cannot be used to establish any relationships or any causeand-effect relationships (Creswell, 2009) ${ }^{[11]}$. Although the information provided in a descriptive research design can be easily interpreted, generalizations are limited.

\subsection{Participants}

Participants in this study were Texas students in Grades 3 through Grade 8 who were enrolled in special education and who attended a public school in the 20122013 through 2015-2016 school years. Data on only students enrolled in special education and who had been as- signed to at least one Disciplinary Alternative Education Program placement were analyzed in this study.

\subsection{Instrumentation and procedures}

For this investigation, the data that were analyzed were accessed from the Texas Education Agency discipline reports, Annual State Summary, which can be located on the Texas Education Agency website. The data provided through the URL is available to the public. Disciplinary data were provided by the Annual State Summary for the 2012-2013 through 2015-2016 school years. The indicated school years were analyzed separately.

In this study, the mathematics achievement scores of students enrolled in special education and the receipt of Disciplinary Alternative Education Program placement was analyzed and compared. The Parent's Guide to the Admission, Review, and Dismissal Process provided by the Texas Education Agency ${ }^{[12]}$ (2016b) defined special education in Texas to be a student between the ages of 3 and 21 who has met the criteria established for one or more of the 13 eligibility categories defined by the state of Texas. The student must have a disability and as a result of that disability, the student must demonstrate a need for specialized services and supports in order to benefit from education (Texas Education Agency, 2016b) ${ }^{[12]}$.

The discipline consequence of a Disciplinary Alternative Education Program placement was analyzed. Disciplinary Alternative Education Program placement is the third method of disciplinary action. Students are removed from the regular classroom and placed in an alternative classroom setting for an extended period of time, not to exceed 45 school days. Disciplinary Alternative Education Program placement may be located on or off campus, but students are educated away from the regular classroom (Texas Education Agency, 2010).

The STAAR is a state readiness program designed to measure students' ability to apply knowledge and skills defined by the Texas Essential Knowledge and Skills in Grades 3 through 12 (Texas Education Agency, Glossary of Acronyms, 2017b) ${ }^{[8]}$. On the STAAR exam, Level I Unsatisfactory Academic Performance label is given to students who are inadequately prepared and who are unlikely to be prepared for the next grade level. These students would likely require extensive academic interventions. The label of Level II Satisfactory Academic Performance is assigned to students who are prepared for the next grade level and who may require very little or no academic intervention. Level II: Phase-In Satisfactory Performance refers to the label given to students who are prepared for the next grade level, by Phase-In 
standards. The Phase-In Standard is 1.0 standard deviations below the Level II Recommended Performance standard reported to be established in the 2021-2022 school year (Texas Education Agency, 2015) ${ }^{[9]}$. Level III Advanced Performance is the label given to students who are well-prepared for the next grade level and who have a high likelihood of success with little or no academic intervention (Texas Education Agency, 2016a, chapter 4, p.26) ${ }^{[10]}$. The discipline consequence assignments of Disciplinary Alternative Education Program placement was analyzed separately for students in Grades 3 through 8. The mathematics achievement of students enrolled in special education during the 2012-2013 through the 2015-2016 school years was analyzed separately by their Disciplinary Alternative Education Program placement.

\section{Results}

To address the research questions regarding Grade 3 through 8 students enrolled in special education who had a STAAR Mathematics Level I: Unsatisfactory Standard performance and who received between 1 to 30 days, between 31-60 days, and more than 60 days in a Disciplinary Alternative Education Program placement in the 2012-2013 through the 2015-2016 school years, descriptive statistics were calculated from the Excel files that were downloaded from the Texas Education Agency website. As revealed in Table 1, the percentage of students in special education who were assigned 1 to 30 days in a Disciplinary Alternative Education Program placement who had a STAAR Mathematics Level I: Unsatisfactory Performance increased for students in Grades 3, 6, and 8, but decreased for students in Grades 4 and 5 in the 2012-2013 school year.

In regard to Grade 3 students who were enrolled in special education and had received between 1-30 days, as presented in Table 1, 65\%, 49\%, and $60 \%$ of them had an Unsatisfactory Standard performance in the 20132014, 2014-2015, and 2015-2016 school year, respectively. Concerning students who had received between $31-60$ days, $76 \%, 79 \%, 75 \%$, and $68 \%$ of them had an Unsatisfactory Standard performance in the 2012-2013, 2013-2014, 2014-2015, and 2015-2016 school year, respectively. For Grade 3 students who received more than 60 days, $57 \%$ of them had an Unsatisfactory Standard performance in the 2012-2013 school year. The percentage of Grade 3 students ranged from $49 \%$ to $65 \%$ for students who were assigned 1-30 days; and from $68 \%$ to $79 \%$ for students who were assigned 31-60 days.

For Grade 4 students, as delineated in Table 1, 72\%, $67 \%, 66 \%$, and $63 \%$ of students who received between 1-30 days in the 2012-2013, 2013-2014, 2014-2015,
Table 1. Percentage of students in special education assigned Disciplinary Alternative Education Program placement in the 2012-2013 school year through the 2015-2016 school year who had mathematics level I: unsatisfactory performance on the STAAR mathematics exam

\begin{tabular}{cccc}
\hline School Year & $\begin{array}{c}1-30 \text { Day } \\
\text { Placement in } \\
\text { DAEP }\end{array}$ & $\begin{array}{c}31-60 \text { Day } \\
\text { Placement in } \\
\text { DAEP }\end{array}$ & $\begin{array}{c}\text { More than } 60 \\
\text { Days Placement } \\
\text { in DAEP }\end{array}$ \\
\hline Grade 3 & & & \\
$2012-2013$ & $59 \%$ & $76 \%$ & $57 \%$ \\
$2013-2014$ & $65 \%$ & $79 \%$ & N/A \\
$2014-2015$ & $49 \%$ & $75 \%$ & N/A \\
$2015-2016$ & $60 \%$ & $68 \%$ & N/A \\
Grade 4 & & & \\
$2012-2013$ & $70 \%$ & $72 \%$ & $72 \%$ \\
$2013-2014$ & $67 \%$ & $74 \%$ & $73 \%$ \\
$2014-2015$ & $66 \%$ & $82 \%$ & $79 \%$ \\
$2015-2016$ & $63 \%$ & $68 \%$ & $79 \%$ \\
Grade 5 & & & \\
$2012-2013$ & $65 \%$ & $68 \%$ & $67 \%$ \\
$2013-2014$ & $56 \%$ & $71 \%$ & $77 \%$ \\
$2014-2015$ & $58 \%$ & $70 \%$ & $61 \%$ \\
$2015-2016$ & $57 \%$ & $68 \%$ & $71 \%$ \\
Grade 6 & & & \\
$2012-2013$ & $61 \%$ & $67 \%$ & $68 \%$ \\
$2013-2014$ & $57 \%$ & $66 \%$ & $73 \%$ \\
$2014-2015$ & $60 \%$ & $68 \%$ & $78 \%$ \\
$2015-2016$ & $62 \%$ & $66 \%$ & $75 \%$ \\
Grade 7 & & & \\
$2012-2013$ & $64 \%$ & $68 \%$ & $75 \%$ \\
$2013-2014$ & $70 \%$ & $77 \%$ & $83 \%$ \\
$2014-2015$ & $63 \%$ & $67 \%$ & $70 \%$ \\
$2015-2016$ & $64 \%$ & $73 \%$ & $77 \%$ \\
Grade 8 & & & $74 \%$ \\
$2012-2013$ & $53 \%$ & $58 \%$ & $61 \%$ \\
$2013-2014$ & $50 \%$ & $56 \%$ & $63 \%$ \\
$2014-2015$ & $60 \%$ & $67 \%$ & \\
$2015-2016$ & $62 \%$ & $68 \%$ & \\
\hline & & & \\
\hline
\end{tabular}

and 2015-2016 school years, respectively, had an Unsatisfactory Standard performance. Concerning Grade 4 students who received between 31-60 days, 54\% and $82 \%$, of them, respectively in the 2013-2014 and 20142015 school years had an Unsatisfactory Standard performance. Regarding students who had received more than 60 days, $72 \%$ and $79 \%$ of them, respectively, had an Unsatisfactory Standard performance in the 2014-2015 and 2015-2016 school years. The percentage of Grade 4 students ranged from $63 \%$ to $70 \%$ for students who were assigned 1-30 days; from $68 \%$ to $82 \%$ for students who were assigned 31-60 days; and from $73 \%$ to $79 \%$ for students who were assigned to more than 60 days.

With respect to Grade 5 students, as presented in Table $1,65 \%, 56 \%, 58 \%$, and $57 \%$ of them who received between 1-30 days had an Unsatisfactory Standard performance in the 2012-2013, 2013-2014, 2014-2015, and 2015-2016 school years, respectively. Concerning Grade 5 students who received between 31-60 days, 68\% and $70 \%$, respectively, had an Unsatisfactory Standard performance in the 2012-2013 and 2014-2015 school year, 
respectively. For Grade 5 students who received more than 60 days, $77 \%$ and $71 \%$ of them had an Unsatisfactory Standard performance in the 2013-2014 and 2015-2016 school years, respectively. The percentage of Grade 5 students who had a Level I Unsatisfactory performance ranged from $56 \%$ to $65 \%$ for students who were assigned 1-30 days; from $68 \%$ to $71 \%$ for students who were assigned $31-60$ days; and from $67 \%$ to $71 \%$ for students who were assigned to more than 60 days.

Concerning Grade 6 students, as delineated in Table 1 , the percentage of Grade 6 students who had a Level I Unsatisfactory performance ranged from $57 \%$ to $62 \%$ for students who were assigned 1-30 days; from $66 \%$ to $68 \%$ for students who were assigned 31-60 days; and from $68 \%$ to $78 \%$ for students who were assigned to more than 60 days. With respect to Grade 7 students, as delineated in Table 1, the percentage of them who had a Level I Unsatisfactory performance ranged from $63 \%$ to $70 \%$ for students who were assigned 1-30 days; from 67\% to 77\% for students who were assigned 31-60 days; and from $70 \%$ to $83 \%$ for students who were assigned to more than 60 days. Regarding Grade 8 students, as presented in Table 1, the percentage of Grade 8 students who had a Level I Unsatisfactory performance ranged from $41 \%$ to $51 \%$ for students who were assigned 1-30 days; from $48 \%$ to $56 \%$ for students who were assigned 31-60 days; and from $51 \%$ to $60 \%$ for students who were assigned to more than 60 days.

A trend was clearly established with respect to the number of students enrolled in special education who had a Level I: Unsatisfactory Standard performance on the STAAR Mathematics exam. The percentage of students in Grades 3 through 8 who received more than 60 days in Disciplinary Alternative Education Program placement and who had Unsatisfactory Standard Performance on the STAAR Mathematics exam increased from the 2012-2013 to the 2015-2016 school year.

Next, the research questions regarding Grade 3 through 8 students enrolled in special education who had a STAAR Mathematics Level II: Satisfactory Standard performance and who received between 1 to 30 days, between 31-60 days, and more than 60 days in a Disciplinary Alternative Education Program placement were addressed. Table 2 contain the descriptive statistics for these research questions.

As revealed in Table 2, 11\%, 10\%, and 13\% of Grade 3 students who received between 1-30 days had a Satisfactory Standard performance in the 2012-2013, 20132014, and 2014-2015 school years, respectively. For Grade 3 students who received between 31-60 days, only 9\% of them had a Satisfactory Standard performance in the 2012-2013 school year. The performance of stu-
Table 2. Percentage of students in special education assigned Disciplinary Alternative Education Program placement in the 2012-2013 school year through the 2015-2016 school year who had mathematics level II: satisfactory performance on the STAAR mathematics exam

\begin{tabular}{|c|c|c|c|}
\hline School Year & $\begin{array}{c}\text { 1-30 Day } \\
\text { Placement in } \\
\text { DAEP }\end{array}$ & $\begin{array}{l}\text { 31-60 Day } \\
\text { Placement in } \\
\text { DAEP }\end{array}$ & $\begin{array}{c}\text { More than } 60 \\
\text { Days Placement } \\
\text { in DAEP }\end{array}$ \\
\hline Grade 3 & & & \\
\hline $2012-2013$ & $11 \%$ & $9 \%$ & N/A \\
\hline 2013-2014 & $10 \%$ & N/A & $0 \%$ \\
\hline 2014-2015 & $13 \%$ & N/A & N/A \\
\hline $\begin{array}{c}2015-2016 \\
\text { Grade } 4\end{array}$ & Missing Data & Missing Data & Missing Data \\
\hline $2012-2013$ & $7 \%$ & $11 \%$ & N/A \\
\hline 2013-2014 & $11 \%$ & $10 \%$ & N/A \\
\hline 2014-2015 & $8 \%$ & N/A & N/A \\
\hline $\begin{array}{c}2015-2016 \\
\text { Grade } 5\end{array}$ & Missing Data & Missing Data & Missing Data \\
\hline $2012-2013$ & $10 \%$ & $6 \%$ & $10 \%$ \\
\hline 2013-2014 & $13 \%$ & $7 \%$ & $0 \%$ \\
\hline 2014-2015 & $10 \%$ & $6 \%$ & N/A \\
\hline $\begin{array}{c}\text { 2015-2016 } \\
\text { Grade } 6\end{array}$ & Missing Data & Missing Data & Missing Data \\
\hline $2012-2013$ & $8 \%$ & $5 \%$ & $3 \%$ \\
\hline 2013-2014 & $8 \%$ & $5 \%$ & $5 \%$ \\
\hline 2014-2015 & $8 \%$ & $6 \%$ & $3 \%$ \\
\hline $\begin{array}{c}\text { 2015-2016 } \\
\text { Grade } 7\end{array}$ & Missing Data & Missing Data & Missing Data \\
\hline $2012-2013$ & $6 \%$ & $5 \%$ & $4 \%$ \\
\hline 2013-2014 & $6 \%$ & $4 \%$ & $2 \%$ \\
\hline 2014-2015 & $7 \%$ & $5 \%$ & $6 \%$ \\
\hline $\begin{array}{c}2015-2016 \\
\text { Grade } 8\end{array}$ & Missing Data & Missing Data & Missing Data \\
\hline $2012-2013$ & $9 \%$ & $8 \%$ & $6 \%$ \\
\hline 2013-2014 & $10 \%$ & $8 \%$ & $5 \%$ \\
\hline 2014-2015 & $9 \%$ & $7 \%$ & $4 \%$ \\
\hline 2015-2016 & Missing Data & Missing Data & Missing Data \\
\hline
\end{tabular}

dents who received more than 60 days for the 2012-2013 through the 2015-2016 school years and for students who received 31-60 days in the 2013-2014 and 2015-2016 school years was not available.

With respect to Grade 4 students, as delineated in Table 2, low percentages, ranging from $7 \%$ to $11 \%$, of them who received a Disciplinary Alternative Education Program placement had a Satisfactory Standard performance. Similar to Grade 4 students, as presented in Table 2 , low percentages, ranging from $0 \%$ to $10 \%$, of Grade 5 students who received a Disciplinary Alternative Education Program placement had a Satisfactory Standard performance. As revealed in Table 2, the percentages of Grade 6 students who received a Disciplinary Alternative Education Program placement and who had a Satisfactory Standard performance ranged from $3 \%$ to $9 \%$. For Grade 7 students, as delineated in Table 2, the percentage of them who had a Level I Satisfactory performance ranged from $10 \%$ to $14 \%$ for students who were assigned 1-30 days; from $8 \%$ to $11 \%$ for students who were as- 
Table 3. Percentage of students in special education assigned Disciplinary Alternative Education Program placement in the 2012-2013 school year through the 2015-2016 school year who had mathematics level II: phase-in satisfactory performance on the STAAR mathematics exam

\begin{tabular}{cccc}
\hline School Year & $\begin{array}{c}1-30 \text { Day } \\
\text { Placement in } \\
\text { DAEP }\end{array}$ & $\begin{array}{c}31-60 \text { Day } \\
\text { Placement in } \\
\text { DAEP }\end{array}$ & $\begin{array}{c}\text { More than } 60 \\
\text { Days Placement } \\
\text { in DAEP }\end{array}$ \\
\hline Grade 3 & & & \\
$2012-2013$ & $41 \%$ & $11 \%$ & $3 \%$ \\
$2013-2014$ & $35 \%$ & $21 \%$ & N/A \\
$2014-2015$ & $51 \%$ & $25 \%$ & N/A \\
$2015-2016$ & $40 \%$ & $32 \%$ & N/A \\
Grade 4 & & & \\
$2012-2013$ & $30 \%$ & $28 \%$ & $28 \%$ \\
$2013-2014$ & $33 \%$ & $26 \%$ & $27 \%$ \\
$2014-2015$ & $34 \%$ & $18 \%$ & $21 \%$ \\
$2015-2016$ & $37 \%$ & $32 \%$ & $21 \%$ \\
Grade 5 & & & \\
$2012-2013$ & $35 \%$ & $32 \%$ & $33 \%$ \\
$2013-2014$ & $44 \%$ & $29 \%$ & $23 \%$ \\
$2014-2015$ & $42 \%$ & $30 \%$ & $39 \%$ \\
$2015-2016$ & $43 \%$ & $32 \%$ & $29 \%$ \\
Grade 6 & & & \\
$2012-2013$ & $39 \%$ & $33 \%$ & $32 \%$ \\
$2013-2014$ & $43 \%$ & $34 \%$ & $27 \%$ \\
$2014-2015$ & $40 \%$ & $32 \%$ & $22 \%$ \\
$2015-2016$ & $38 \%$ & $34 \%$ & $25 \%$ \\
Grade 7 & & & \\
$2012-2013$ & $36 \%$ & $32 \%$ & $25 \%$ \\
$2013-2014$ & $30 \%$ & $23 \%$ & $17 \%$ \\
$2014-2015$ & $37 \%$ & $33 \%$ & $30 \%$ \\
$2015-2016$ & $36 \%$ & $27 \%$ & $23 \%$ \\
Grade 8 & & & \\
$2012-2013$ & $47 \%$ & $42 \%$ & $46 \%$ \\
$2013-2014$ & $50 \%$ & $44 \%$ & $39 \%$ \\
$2014-2015$ & $40 \%$ & $33 \%$ & $27 \%$ \\
$2015-2016$ & $38 \%$ & $32 \%$ & $21 \%$ \\
\hline & & &
\end{tabular}

signed 31-60 days; and from 6\% to 9\% for students who were assigned to more than 60 days. Concerning Grade 8 students, as presented in Table 2, the percentage of them who had a Level II Satisfactory performance ranged from $9 \%$ to $10 \%$ for students who were assigned 1-30 days; from $7 \%$ to $8 \%$ for students who received between 31-60 days; and from $4 \%$ to $6 \%$ for students who were assigned more than 60 days.

Next, the research questions regarding Grade 3 through 8 students enrolled in special education who had a STAAR Mathematics Level II: Phase-In Satisfactory Standard performance and who received a Disciplinary Alternative Education Program placement were addressed. As revealed in Table 3, the percentage of students in special education who were assigned 1 to 30 days and had a Level II: Phase-In Satisfactory Performance on the STAAR Mathematics exam decreased from the 2012-2013 school year to the 2015-2016 school year for all grade levels except for Grade 4 and 5. No change was present for Grade 7.

In regard to Grade 3 students, as presented in Table 3,
$41 \%, 35 \%, 51 \%$, and $40 \%$ of the students who received between 1-30 days had a Phase-In Satisfactory Standard performance in the 2012-2013, 2013-2014, 20142015 , and 2015-2016 school years, respectively. Concerning Grade 3 students who received between 31-60 days, $21 \%, 25 \%$, and $32 \%$ of Grade 3 students who received between 31-60 days had a Phase-In Satisfactory Standard performance in the 2013-2014, 2014-2015, and 2015-2016 school years, respectively. A very low percentage, $3 \%$, of students who received more than 60 days had a Phase-In Satisfactory Standard performance in the 2012-2013 school year. The percentage of Grade 3 students who had a Level II: Phase-In Satisfactory performance ranged from $35 \%$ to $51 \%$ for students who were assigned 1-30 days; from $11 \%$ to $32 \%$ for students who were assigned 31-60 days; and 3\% for students who received more than 60 days.

With respect to Grade 4 students, as delineated in Table $3,30 \%, 33 \%, 34 \%$, and $37 \%$ of them who received between 1-30 days had a Phase-In Satisfactory Standard performance in the four school years, respectively. Concerning Grade 4 students who received between 3160 days, $28 \%, 26 \%$, and $18 \%$ of them had students had a Phase-In Satisfactory Standard performance in the 2012-2013, 2013-2014, and 2014-2015 school years, respectively. Regarding students who had more than 60 days, $28 \%$ and $21 \%$ of them had a Phase-In Satisfactory Standard performance in the 2012-2013 and 2015-2016 school years, respectively. The percentage of Grade 4 students who had a Level II: Phase-In Satisfactory performance ranged from $30 \%$ to $37 \%$ for students who were assigned 1-30 days; from $18 \%$ to $32 \%$ for students who were assigned 31-60 days; and from $21 \%$ to $28 \%$ for students who were assigned more than 60 days.

Concerning Grade 5 students, as presented in Table 3, $35 \%, 44 \%, 42 \%$, and $43 \%$ of them who received between 1-30 days had a Phase-In Satisfactory Standard performance in the four school years, respectively. For the students who received between 31-60 days, $32 \%$ and 30\% of them who received between 31-60 days had a Phase-In Satisfactory Standard performance in the 2012-2013 and 2014-2015 school years, respectively. Regarding Grade 5 students who received more than 60 days, $23 \%$ and $29 \%$ of them had a Phase-In Satisfactory Standard performance in the 2013-2014 and 2015-2016 school years, respectively. The percentage of Grade 5 students who had a Level II: Phase-In Satisfactory performance ranged from $35 \%$ to $44 \%$ for students who were assigned 1-30 days; from $29 \%$ to $32 \%$ for students who were assigned 31-60 days; and from $29 \%$ to $39 \%$ for students who were assigned more than 60 days.

With respect to Grade 6 students, as revealed in Ta- 
ble $3,39 \%, 43 \%, 40 \%$, and $38 \%$ of them who received between 1-30 days had a Level II: Phase-In Satisfactory Standard performance in the 2012-2013, 2013-2014, 2014-2015, and 2015-2016 school years, respectively. For students who received more than 60 days, 32\%, 27\%, $22 \%$, and $25 \%$ of them had a Phase-In Satisfactory Standard performance in the four school years, respectively. The percentage of Grade 6 students who had a Level II: Phase-In Satisfactory performance ranged from $38 \%$ to $43 \%$ for students who were assigned 1-30 days; from $32 \%$ to $34 \%$ for students who were assigned 31-60 days; and from $22 \%$ to $32 \%$ for students who were assigned to more than 60 days.

Concerning Grade 7 students who were enrolled in special education and who had a Level II: Phase-In Satisfactory Standard performance on the STAAR Mathematics exam, the percentages ranged from $30 \%$ to $37 \%$ for students who were assigned 1-30 days; from $30 \%$ to $42 \%$ for students who were assigned 31-60 days from 27\%-33\%; and from $17 \%$ to $30 \%$ for Grade 7 students who were assigned to more than 60 days. These percentages are contained in Table 3 . With respect to Grade 8 students who were enrolled in special education and who had a Level II: Phase-In Satisfactory Standard performance on the STAAR Mathematics exam, their percentages ranged from $38 \%$ to $50 \%$ for students who were assigned 1-30 days; from $32 \%$ to $44 \%$ for students who were assigned 31-60 days; and from $21 \%$ to $46 \%$ for Grade 8 students who were assignged to more than 60 days.

The percentage of students in special education who were assigned more than 60 days and who had Mathematics Level II: Phase-In Satisfactory Performance decreased from the 2012-2013 school year to the 20152016 school year for all grade levels. The percentage of students in special education who were assigned 1 to 30 days varied from a 9 percentage point decrease for students in Grade 8 to an 8 percentage point increase for students in Grade 5. The percentage of students in special education who were assigned 31-60 days varied from a 10 percentage point decrease for students in Grade 8 to a 21 percentage point increase for students in Grade 3 .

Next, the research questions on Grade 3 through 8 students enrolled in special education who had a STAAR Mathematics Level III: Advanced Performance and received between 1 to 30 days, between 31-60 days, and more than 60 days during the 2012-2013 through the 2015-2016 school years were addressed. As revealed in Table 4, data provided for students who had Advanced Standard performance were limited.

With respect to Grade 3 students who were enrolled in special education and who had a Level III: Ad-
Table 4. Percentage of students in special education assigned Disciplinary Alternative Education Program placement in the 2012-2013 school year through the 2015-2016 school year who had mathematics level III: advanced performance on the STAAR mathematics exam

\begin{tabular}{|c|c|c|c|}
\hline School Year & $\begin{array}{c}\text { 1-30 Day } \\
\text { Placement in } \\
\text { DAEP }\end{array}$ & $\begin{array}{l}\text { 31-60 Day } \\
\text { Placement in } \\
\text { DAEP }\end{array}$ & $\begin{array}{c}\text { More than } 60 \\
\text { Days Placement } \\
\text { in DAEP }\end{array}$ \\
\hline \multicolumn{4}{|l|}{ Grade 3} \\
\hline $2012-2013$ & $3 \%$ & $\mathrm{~N} / \mathrm{A}$ & $\mathrm{N} / \mathrm{A}$ \\
\hline $2013-2014$ & $3 \%$ & N/A & $0 \%$ \\
\hline 2014-2015 & $2 \%$ & N/A & $0 \%$ \\
\hline $2015-2016$ & $5 \%$ & N/A & $0 \%$ \\
\hline \multicolumn{4}{|l|}{ Grade 4} \\
\hline $2012-2013$ & $3 \%$ & $10 \%$ & $0 \%$ \\
\hline 2013-2014 & $3 \%$ & N/A & N/A \\
\hline 2014-2015 & $2 \%$ & N/A & $0 \%$ \\
\hline $2015-2016$ & $4 \%$ & N/A & $0 \%$ \\
\hline \multicolumn{4}{|l|}{ Grade 5} \\
\hline $2012-2013$ & $3 \%$ & N/A & N/A \\
\hline 2013-2014 & $5 \%$ & $4 \%$ & $0 \%$ \\
\hline 2014-2015 & $2 \%$ & N/A & N/A \\
\hline $2015-2016$ & $3 \%$ & $3 \%$ & N/A \\
\hline \multicolumn{4}{|l|}{ Grade 6} \\
\hline $2012-2013$ & $1 \%$ & N/A & $1 \%$ \\
\hline 2013-2014 & $2 \%$ & $1 \%$ & N/A \\
\hline $2014-2015$ & $1 \%$ & N/A & N/A \\
\hline $2015-2016$ & $2 \%$ & $1 \%$ & N/A \\
\hline \multicolumn{4}{|l|}{ Grade 7} \\
\hline $2012-2013$ & $1 \%$ & $1 \%$ & N/A \\
\hline 2013-2014 & $1 \%$ & $1 \%$ & N/A \\
\hline 2014-2015 & $1 \%$ & $1 \%$ & N/A \\
\hline 2015-2016 & $2 \%$ & $1 \%$ & N/A \\
\hline \multicolumn{4}{|l|}{ Grade 8} \\
\hline $2012-2013$ & $0 \%$ & N/A & $0 \%$ \\
\hline 2013-2014 & $1 \%$ & $0 \%$ & N/A \\
\hline 2014-2015 & $1 \%$ & $0 \%$ & N/A \\
\hline $2015-2016$ & $1 \%$ & $0 \%$ & N/A \\
\hline
\end{tabular}

vanced Standard performance on the STAAR Mathematics exam, the percentages of students who received between 1-30 days and who had an Advanced Satisfactory Standard performance were low, ranging from $2 \%$ to $5 \%$. Concerning Grade 4 students who were enrolled in special education and who had a Level III: Advanced Standard performance, no students who received more than 60 days had an Advanced Satisfactory Standard performance. In contrast, $10 \%$ of students who received between 31-60 days had a Level III: Advanced Standard Performance. The percentage of Grade 4 students who were assigned between 1-30 days and who had a Level III: Advanced Standard Performance ranged from 3\% to $4 \%$.

Regarding Grade 5 students who were enrolled in special education, very low percentages of them had a Level III: Advanced Standard performance, with percentages ranging from $3 \%$ to $5 \%$. Similar results were present for Grade 6 students who were enrolled in special education, with the percentages of them who had a Level III: Advanced Standard Performance ranging from $1 \%$ 
to $2 \%$. With respect to Grade 7 students, the percentages of them who had a Level III: Advanced Standard Performance were similarly poor, ranging from $1 \%$ to $2 \%$. Concerning Grade 8 students, percentages ranged from $0 \%$ to $1 \%$ for students who had a Level III: Advanced Standard Performance on the STAAR Mathematics exam.

\section{Discussion}

In this investigation, the percentage of students who were enrolled in special education and who were assigned a Disciplinary Alternative Education Program placement between 1-30 days, between 31-60 days, and more than 60 days and who had a STAAR Mathematics Level I: Unsatisfactory, STAAR Mathematics Level II: Satisfactory, STAAR Mathematics Level II: PhaseIn Satisfactory, and STAAR Mathematics Level III: Advanced Standard. Student placement during the 20122013 through 2015-2016 school years were addressed. Four school years of statewide archival data were analyzed from the Texas Education Agency ${ }^{[13]}$. Following the analysis of all four school years of data, trends were identified in the assignment of Disciplinary Alternative Education Program placement and the mathematics performance of students who were enrolled in special education. The longer the duration of placement, the lower the student performance was in mathematics. Students who were placed in a Disciplinary Alternative Education Program placement between 1-30 days had better mathematics performance than their peers who received 31-60 days or who received more than 60 days in almost every grade level across the four years examined. In the data analyzed, the highest percentage of students had an Unsatisfactory Performance on the STAAR Mathematics exam.

\subsection{Connections to existing literature}

In this 4-year statewide investigation, results were congruent with previous researchers (e.g., Allman \& Slate, 2012, 2013; Arcia, 2006; Benson \& Slate, $2017)^{[3-5,14]}$ regarding the influence of exclusionary discipline consequences on student academic performance. In this empirical statewide investigation, the assignment of a Disciplinary Alternative Education Program placement and the mathematics performance of students who were enrolled in special education were addressed. Previous researchers (e.g., Allman \& Slate, 2012, 2013; Arcia, 2006; Benson \& Slate, 2017) ${ }^{[3-5,14]}$ have documented that the assignment of exclusionary discipline consequences negatively influences the achievement of students in special education. In this investigation, the highest percentage of students enrolled in special education had Mathematics Level I: Unsatisfactory Performance across all four school years and all grade levels, in comparison to the percentage of students who had a Mathematics Level II: Satisfactory Performance, Mathematics Level II: Phase-In Satisfactory Performance, and Mathematics Level III: Advanced Performance.

When examining the percentage of students in special education who were assigned between 1-30 days, between 31-60 days, and more than 60 days to a Disciplinary Alternative Education Program placement and had Mathematics Level I: Unsatisfactory Performance, the percentage of students increased from the 2012-2013 to the 2015-2016 school year for Grades 3 through 8 students who received more than 60 days of this consequence. The percentage of students who received more than 60 days and had Satisfactory and Phase-In Satisfactory Standard performance decreased for all grade levels over the four years investigated except for Grade 8 students who had a Satisfactory Standard performance. As such, the percentage of students in special education who received a Disciplinary Alternative Education Program placement of more than 60 days, and who were unlikely to succeed in the next grade level increased from the 2012-2013 school year to the 2015-2016 school year for Grades 3 through 8 students. For Grades 7 and 8 students, the percentage of students who had Unsatisfactory Standard performance increased for all students who received a Disciplinary Alternative Education Program placement.

\subsection{Implications for policy and practice}

Based upon the results of the multi-year, Texas statewide investigation, several implications for policy and for practice can be made. First, educational leaders and policymakers are encouraged to examine and implement performance standards that are consistent and easily interpreted by parents and educators. These educational leaders should consider the influence of standardized assessments on students in special education, their teachers, and families. An increase in the performance standard in the 2015-2016 school year without adequate explanations provided to the public yielded a substantial decline in the performance of all students.

Educational leaders and school administrators should also be mindful of the implications of exclusionary discipline assignments on student success. Are the students who are assigned these exclusionary discipline assignments repeating the non-preferred behavior, resulting in increased exclusion from the classroom? Based upon that information, educational leaders could improve dis- 
cipline programs and investigate a behavioral curriculum which may allow more individualized behavioral intervention for students in special education. District and campus leaders should investigate the instruction, support, and resources provided to students who are placed in a Disciplinary Alternative Education Program.

A third implication is to examine school district Manifestation Determination Review procedures and decision making process. Federal legislation was implemented to ensure students in special education are not excessively excluded from the classroom due to behavior which are a manifestation of their disability. This decision is determined by a committee of educators and the parents or adult student. School district leaders should examine the training, education, and experience of the members of this committee. School leaders should collect data on the number of meetings held and decisions handed down by the committee to be mindful of trends in offense, and length and frequency of disciplinary assignments received by students in special education. Documentation in Individualized Education Plans should be investigated to determine appropriate services and supports are provided.

\subsection{Recommendations for future research}

Based upon the results of this multiyear, statewide investigation, several recommendations for future research can be made. First, researchers are encouraged to determine the degree to which the results obtained herein on all students in special education might be generalizable to boys only and to girls only. A second recommendation is to ascertain the extent to which student economic status might be a factor, both in the assignment to a disciplinary consequence and to the academic achievement of students who receive a disciplinary consequence. A third suggestion would be to analyze the degree to which student ethnicity/race might be a factor in student assignment to a disciplinary consequence and to their academic performance.

A fourth recommendation would be to extend this investigation to other grade levels. In this article, data on only students in Grades 3 through 8 were analyzed. Whether the results of this article are generalizable to students in special education in other grade levels is not known. Fifth, researchers are encouraged to extend this investigation to other subject areas such as reading, writing, science, and social studies. A sixth recommendation would be to extend this study to other states. The extent to which the findings from this investigation conducted on Texas students would be generalizable to students in other states is not known.
As readers are aware, findings delineated herein were based on students in Texas. The degree to which our findings would be generalizable to students in other states and in countries other than the United States is not known. As such, researchers are encouraged to replicate this investigation with students who have received similar exclusionary discipline consequences as the students in this study. Not only should the subject area of mathematics be addressed, but other subject areas such as reading and science should also be examined. More research studies are clearly needed into this area to determine the degree to which results obtained on students in the United States would be generalizable to students in other countries.

As suggested to us by one of this article's reviewers, future researchers are encouraged to take the results of this single state study, Texas, and compare and contrast the findings herein with findings from the international research literature. Because of the way that the data analyzed in this investigation were made available, inferential statistics were not possible. That is, the State of Texas provided the data only in aggregated or summarized form. Accordingly, researchers are encouraged to obtain data that would permit the use of inferential statistics. Such analyses would provide more confidence in the findings that are permitted with the sole use of descriptive statistics.

\section{Conclusion}

In this study, the performance of students who were enrolled in special education and who were assigned to a Discipline Alternative Education Program placement on the Texas state-mandated mathematics assessment was examined for four school years. Using statewide data on Grades 3 through 8 students, the number of days students were assigned to a Discipline Alternative Education Program placement was determined to be related to student mathematics performance. The passing rates of students declined as the number of days assigned went from 1-30, $31-60$, and more than 60 days in this discipline consequence.

\section{References}

[1] The National Council on Disability. (2015). Breaking the school-to-prison pipeline for students with disabilities. 529. Retrieved from https://www.ncd.gov/sites/default/files/ Documents/NCD_School-to-PrisonReport_508-PDF.pdf

[2] Individuals with Disabilities Education Act. 20 U.S.C 1401 et seq., 2004.

[3] Benson JH and Slate JR. Differences in academic achievement by disciplinary consequence assignments for students 
with learning disabilities: A within groups comparison. Sam Houston State University, Huntsville, TX, 2018.

[4] Allman KL and Slate JR. Disciplinary consequence effects on the achievement of students with disabilities: A statewide examination. Journal of Education Research, 2012, 6(4): 369-384.

[5] Allman KL and Slate JR. Disciplinary consequences assigned to students with Emotional Disorder, Learning Disability, or Other Health Impairment: Effects on their academic achievement. Journal of Education Research, 2013, 7(1): 83-101.

[6] Sullivan AL, Van Norman ER and Klingbeil DA. Exclusionary discipline of students with disabilities: Student and school characteristics predicting suspension. Remedial and Special Education, 2014, 35(4): 199-210. https://doi.org/10.1177/0741932513519825

[7] Lewis KR. Why schools over-discipline children with disabilities, 2015. Retrieved from https://www.theatlantic.com/education/archive/2015/ 07/school-discipline-children-disabilities/399563

[8] Texas Education Agency. Glossary of acronyms, 2017b. Retrieved from http://tea.texas.gov/About_TEA/Glossary_of Acronyms/\#S
[9] Texas Education Agency. STAAR Standard Setting Q\&A, 2015. Retrieved from https://tea.texas.gov/WorkArea/ DownloadAsset.aspx id=25769811319

[10] Texas Education Agency. Parent's Guide to the Admission, review, and Dismissal Process, 2016a. Retrieved from https: //framework.esc18.net/Documents/ARD_Guide_ENG.pdf

[11] Creswell JW. (2009). Research design: Qualitative, quantitative, and mixed methods approaches (3rd ed.). Thousand Oaks, CA: Sage.

[12] Texas Education Agency. STAAR: Technical digest 2014-2015, 2016b. Retrieved from http://tea.texas.gov/ Student_Testing_and_Accountability/Testing/Student_ Assessment_Overview/Technical_Digest_2015-2016

[13] Texas Education Agency. Annual State Summary 20052006 through 2015-2016, 2017a. Retrieved from https:// rptsvr1.tea.texas.gov/adhocrpt/Disciplinary_Data_Products/ Download_State_Summaries.html

[14] Arcia E. Achievement and enrollment status of suspended students: Outcomes in a large, multicultural school district. Education and Urban Society, 2006, 38(3): 359-369. https://doi.org/10.1177/0013124506286947 